\title{
Contrasting Development and Decay Processes of Indian Ocean Dipoles in the 2000s
}

\author{
Takanori Horii, Iwao Ueki, and Kentaro Ando \\ Research Institute for Global Change, JAMSTEC, Yokosuka, Japan
}

\begin{abstract}
We investigated ocean mixed layer temperature (MLT) balance using moored buoy data together with satellite and atmospheric reanalysis datasets in the eastern Indian Ocean for 2002-2012, a period during which six positive and two negative Indian Ocean Dipole (IOD) events were observed. We focused on the location $5^{\circ} \mathrm{S}, 95^{\circ} \mathrm{E}$ where in situ measurements of more than 10 years by a TRITON buoy were available. Heat balance analysis demonstrated that horizontal heat advection mainly produced MLT anomalies and that air-sea heat fluxes had a damping effect during the development phase of IOD events. In contrast, during the decay phase, air-sea heat fluxes had a primary role in suppressing MLT anomalies, causing decay of the anomalous IOD conditions. The contributions of horizontal heat advections differed in events, which may be attributed to diversity of IOD evolutions. These results suggest that IOD involves variety of feedback processes during the development and decay phases.

(Citation: Horii, T., I. Ueki, and K. Ando, Contrasting development and decay processes of Indian Ocean Dipoles in the 2000s. SOLA, 9, 183-186, doi:10.2151/sola.2013-041.)
\end{abstract}

\section{Introduction}

The IOD is a coupled ocean-atmosphere phenomenon in the tropical Indian Ocean (Saji et al. 1999; Webster et al. 1999). Previous studies have shown that IOD affects local, regional, and global climate via changes of atmospheric circulation (e.g., Saji and Yamagata 2003; Cai et al. 2011). Therefore a better understanding of the process and hence better prediction skill of IOD are important issues for climate study. However, accurate predictions of IOD are challenging compared with predicting an El Niño or La Niña (ENSO) event (Luo et al. 2007), largely because of the complex processes of ocean-atmosphere interactions caused by the Indian Monsoon and intraseasonal variability in the tropical Indian Ocean (see Schott et al. 2009 for a review).

A positive IOD is characterized by a cold (warm) sea surface temperature (SST) anomaly in the southeastern (central-western) tropical Indian Ocean (Fig. 1a). In the opposite phase of the IOD, a negative IOD, a warm SST anomaly in the southeastern tropical Indian Ocean (SETIO) co-occurs with a cold SST anomaly in the central-western Indian Ocean (Fig. 1b). The development of these SST anomalies is attributed to air-sea coupled feedback (e.g., Saji et al. 1999; Li et al. 2003), which involves wind-thermocline-SST (Bjerknes) feedback (Bjerknes 1969) and wind-evaporation-SST (WES) feedback (Xie and Philander 1994). Various reanalysisbased and modeling studies have come to different conclusions about the relative importance of air-sea flux and ocean dynamics during the development and decay of IOD. One reason for these varying conclusions is a lack of in-situ observations in the Indian Ocean. Another factor may be the diversity of IOD events over the last few decades, such as differing timings of onset, development, peak, and decay, as well as their various amplitudes (e.g., Du et al. 2013). Further validation is required to quantify the heat exchange related to ocean-atmosphere interactions associated with IOD events.

The Indian Ocean observational network has improved drama-

Corresponding author: Takanori Horii, Japan Agency for Marine-Earth Science and Technology (JAMSTEC), 2-15, Natsushima, Yokosuka, Kanagawa 237-0061 Japan. E-mail: horiit@jamstec.go.jp. (C2013, the Meteorological Society of Japan. (a) Positive IOD Composite

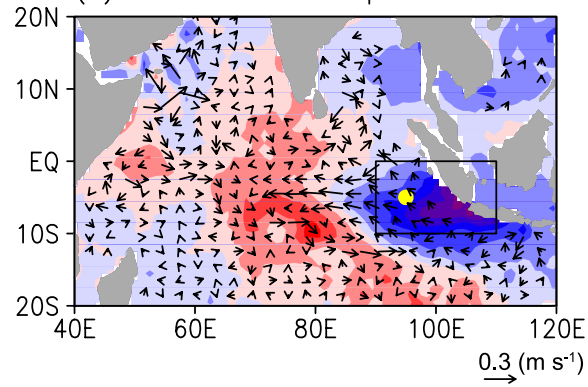

(b) Negative IOD Composite

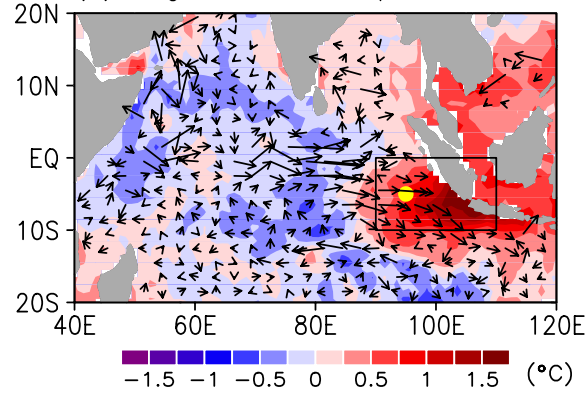

Fig. 1. Composite maps of TMI-SST anomalies and ocean surface current anomalies at peaks \pm 15 days of IOD events. (a) Composite of positive IOD for the 2003, 2006, 2007, 2008, 2011, and 2012 events. (b) Composite of negative IOD for the 2005 and 2010 events. The black square represents the eastern domain $\left(90^{\circ} \mathrm{E}-110^{\circ} \mathrm{E}, 10^{\circ} \mathrm{S}-0^{\circ} \mathrm{S}\right)$ for the calculation of dipole mode index (Saji et al. 1999). The yellow circle indicates the location of a TRITON buoy used in this study.

tically since the mid-2000s, by the development of a new moored buoy array: the Research Moored Array for African-Asian-Australian Monsoon Analysis and Prediction (RAMA; McPhaden et al. 2009). The Argo array has also provided abundant subsurface observation data for studying seasonal to interannual variations (http://www.argo.ucsd.edu). Many IOD events have been observed since the 2000s (e.g., Rao et al. 2009; Xie et al. 2010); the six positive and two negative IOD events during the last decade (Figs. 1,2) provide a good opportunity to examine the processes that induce anomalous SST, based on these newly available data. Quantitative findings from direct observations can be informative in climate research, even with spatially limited data. Although we have conducted case studies for major IOD events during the same period (Horii et al. 2009; 2013), to date no studies have focused on all IOD events and the essential feedback processes during the period including the recent 2011 and 2012 events. In this study, using the buoy measurements together with Argo, satellite, and reanalysis products, we analyzed the MLT balance in SETIO for 2002-2012 to clarify the processes that produced the anomalous SST related to the IOD events. Because our focus was the anomalous SST in the SETIO region, we use the term 'cold (warm) event' instead of 'positive (negative) IOD' in this paper.

\section{Data and method}

We used daily average data from a moored buoy of the Triangle Trans-Ocean Buoy Network (TRITON) deployed at $5^{\circ} \mathrm{S}, 95^{\circ} \mathrm{E}$ by the Japan Agency for Marine-Earth Science and Technology (JAMSTEC). This buoy observes subsurface temperature and sa- 
linity, meteorological variables (wind, air temperature, humidity, shortwave radiation, etc.), and ocean surface currents every 10 min. The location of the buoy allowed us to observe oceanic and atmospheric conditions at the eastern pole of the IOD (Fig. 1). Although there have been some other mooring buoys in SETIO, the buoy at $5^{\circ} \mathrm{S}, 95^{\circ} \mathrm{E}$ has provided the longest time series in RAMA, from October 2001 to the present (http://www.pmel.noaa.gov/tao/ rama/). We also used a monthly temperature and salinity dataset based on Argo floats (Hosoda et al. 2008), to fill data gaps (12\%) in the buoy data. Although interpolation errors from the use of the Argo data are insignificant for climatology calculations (Horii et al. 2013), a data gap between August 2008 and February 2009 caused a relatively larger error in our examination of the evolution of the 2008 IOD.

To clarify the processes controlling MLT variation in SETIO, we analyzed the temperature balance in the ocean mixed layer at $5^{\circ} \mathrm{S}, 95^{\circ} \mathrm{E}$ by

$$
\frac{\partial T}{\partial t}=\frac{\left(Q_{0}+Q_{\mathrm{pen}}\right)}{\rho C_{p} H}-U T_{x}-V T_{y}+R,
$$

where $T$ is the MLT, $\partial T / \partial t$ represents the time rate of its change, $\rho$ is seawater density, $C_{p}$ is heat capacity, and $H$ is mixed layer depth (MLD). MLD was estimated by a density criterion equivalent to an ocean temperature change of $0.5^{\circ} \mathrm{C}$ from the surface (Sprintall and Tomczak 1992). $Q_{0}$ is the net heat flux across the air-sea interface, which consists of radiation and turbulent heat fluxes. $Q_{\text {pen }}$ represents shortwave radiation penetrating below the mixed layer and was estimated following Paulson and Simpson (1977). The terms $-U T_{x}$ and $-V T_{y}$ represent zonal and meridional heat advection, respectively. $R$ is the residual, which consists of components that we could not estimate directly from the observational data, such as the horizontal and vertical diffusion. The residual also includes analysis and sampling errors. The simplified temperature balance worked well for diagnosing the ocean thermodynamic balance associated with cold/warm events (Horii et al. 2009; 2013). For more detail of methodology, see these references.

Because the buoy meteorological observations had non-negligible missing values, we used satellite-based and reanalysis airsea flux datasets after validations. We used turbulent heat fluxes obtained from the Objectively Analyzed air-sea heat Fluxes (OAFlux; Yu and Weller 2007). Longwave radiation was taken from National Centers for Environmental Prediction/National Center for Atmospheric Research (NCEP/NCAR) reanalysis products (Kalnay et al. 1996). Shortwave radiation data for 2002-2009 were obtained from the dataset of the International Satellite Cloud Climatology Project (ISCCP) (Zhang et al. 2004). Because shortwave data were relatively well observed by the buoy during $2010-$ $2012(79 \%)$, we used the buoy data for this period. Missing values during these 3 years were interpolated by utilizing outgoing longwave radiation (OLR) data (Liebmann and Smith 1996), following Foltz et al. (2010). All of these alternative flux datasets were validated by comparison with direct observations from the buoy.

We used horizontal velocity data from the Ocean Surface Current Analysis-Real Time dataset (OSCAR; Bonjean and Lagerloef 2002). Horizontal temperature gradients were calculated from Tropical Rainfall Measuring Mission Microwave Imager (TMI) SST. We combined these data to calculate horizontal advection terms.

To focus on time scales longer than 1 week, all daily data were smoothed with an 11-day running mean filter. For discussions of the climatology and anomaly of the heat balance, climatologies were defined as the 11-year mean (2002-2012), in which the data were smoothed with a 31-day running mean filter. For more detail about the data validations and error estimate, see Horii et al. (2013).

\section{Diagnosis of mixed layer temperature variation}

Cold/warm events during the study period exhibited different evolutions in terms of their timings of onset, peak, and decay, as well as their amplitudes (Fig. 2). The MLT anomalies at $5^{\circ} \mathrm{S}, 95^{\circ} \mathrm{E}$ and their evolutions observed by the buoy were roughly the same as the SST anomalies averaged for the eastern pole of the IOD, although their phases and amplitudes differed somewhat. Although the peak of the negative anomaly at $5^{\circ} \mathrm{S}, 95^{\circ} \mathrm{E}$ was small $\left(-0.33^{\circ} \mathrm{C}\right)$, we included the 2003 cold event in our analysis following previous studies (e.g., Rao and Yamagata 2004; Du et al. 2013). We defined the development phase and decay phase of cold/warm events (Fig. 2) as follows. First, we set the peak of the cold (warm) event as the minimum (maximum) MLT anomaly. For the 2007 and 2011 cases, we set the first and second peaks. Then, we defined the beginning and end of consecutive cold/warm anomalies as the onset and termination of the events, respectively. Finally, we defined the development phase as the period of onset-(first) peak, and defined the decay phase as (second) peak-termination.

The MLT variations at $5^{\circ} \mathrm{S}, 95^{\circ} \mathrm{E}$ were well explained by the sum of the net surface heat flux and horizontal heat advection (Horii et al. 2013; Supplement 1). This implies that horizontal advection indirectly represents contributions from ocean vertical processes, as strengthened/weakened advection of cold water originally entrained in the coastal region, because our study location was approximately $500 \mathrm{~km}$ from the coast of Sumatra. Local entrainment at the buoy location was not completely negligible but was relatively small (Halkides and Lee 2009; Horii et al. 2009). Because our objective was to diagnose essential feedback processes common to the IOD events, we do not describe the details of
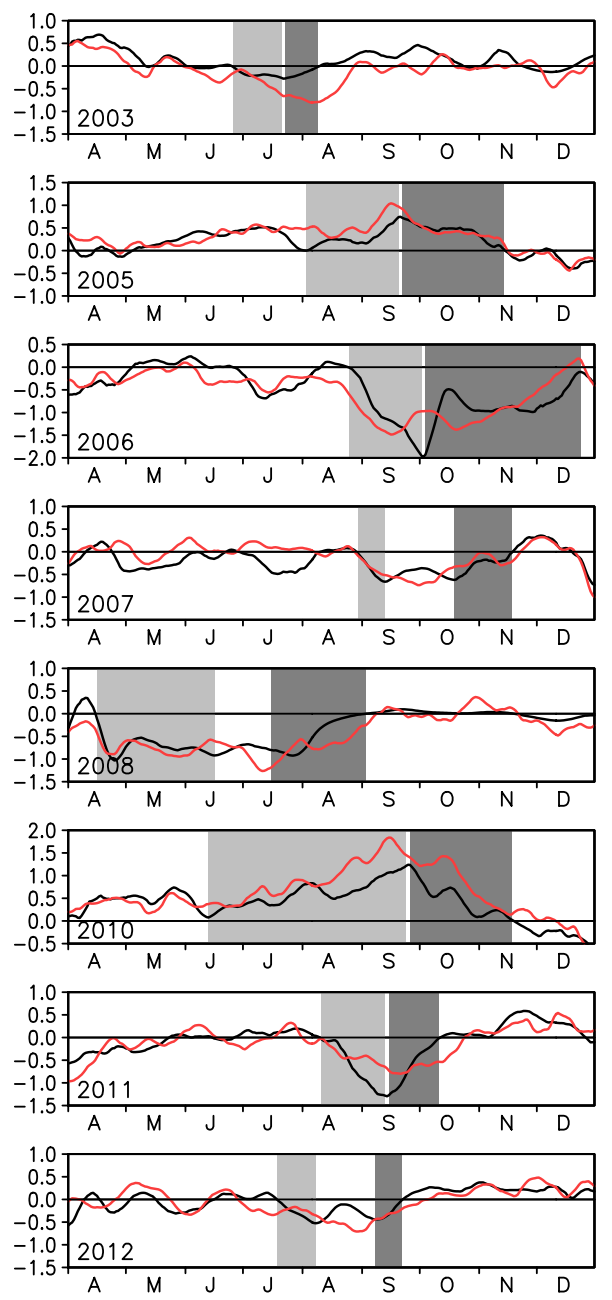

Fig. 2. Time series of the mixed layer temperature anomaly from the TRITON buoy at $5^{\circ} \mathrm{S}, 95^{\circ} \mathrm{E}$ (black line) and SST anomaly averaged for the region $90^{\circ} \mathrm{E}-110^{\circ} \mathrm{E}, 10^{\circ} \mathrm{S}$-equator (red line) for eight IOD events. The data were smoothed with an 11-day running mean filter. The climatologies are defined as the mean seasonal cycle from 2001 to 2012. Light (dark) gray shades indicate the development (decay) phase of the IOD events. 
each event here. Instead, we focus on the relative importance of air-sea flux and horizontal heat advection for MLT change $(\Delta T)$ during the development/decay phases of these cold/warm events in SETIO, based on the MLT balance analysis.

\subsection{Development phase}

During almost all of the development phases of cold/warm events, ocean advections, rather than air-sea heat exchanges, were responsible for the anomalous MLT, even when the errors were considered (Fig. 3). In general, air-sea flux had damping effects on the cooling tendency of MLT anomalies during cold events (Fig. $3 a)$. There, anomalous heat gain due to enhanced shortwave radiation under the clear-sky condition was more effective than enhanced latent heat loss due to strengthening wind (figure not shown). In contrast, most of the horizontal advections contributed to the cooling of MLT anomalies in the cold events (Fig. 3b). The cold advections were mainly the result of anomalous zonal surface currents and anomalous temperature gradients, as clarified in Fig. 1a.

For the two warm events, horizontal advections also had significant contributions for the MLT warming (Fig. 3b). The anomalous advections were produced by the southeastward surface current which brought warmer water to the SETIO. In contrast with the cold events, air-sea flux also contributed to the anomalous MLT warming, although the amplitudes were insignificant (Fig. $3 a)$. The flux anomalies were due to anomalously reduced latent heat losses at this phase.

\subsection{Decay phase}

During the decay phase of the cold/warm events, air-sea fluxes were more responsible for the anomalous MLT variations (Fig. 4). Anomalous heat gains due to enhanced shortwave radiation and reduced latent heat loss effectively caused the decay of the two major cold events (2006 and 2011; Fig. 4a), consistent with previous studies (e.g., Tokinaga and Tanimoto 2004). For the major cold events, horizontal advections counteracted the warming tendencies (Fig. 4b) because anomalous ocean conditions remained and anomalous ocean currents continued to transport colder water

(a) Flux in IOD Development
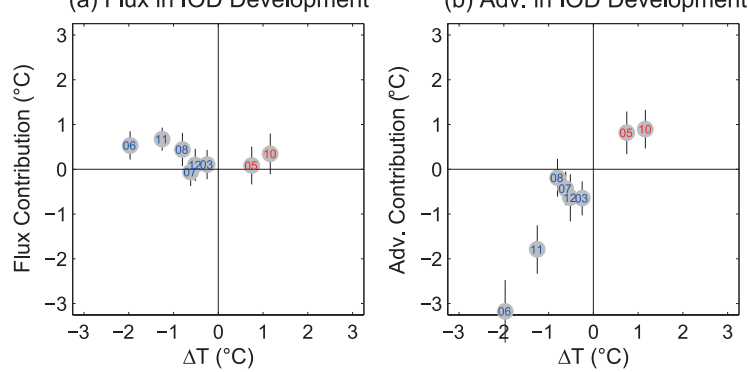

Fig. 3. Scatterplots of mixed layer temperature change and heat balance terms at $5^{\circ} \mathrm{S}, 95^{\circ} \mathrm{E}$ : (a) net air-sea flux and (b) horizontal advection for the development phase of six cold events and two warm events. The blue (red) characters represent positive (negative) IOD events. The numeral pairs denote the last two digits of the year (e.g., '03' means '2003'). The vertical bars denote the error range in the mixed layer temperature balance analysis averaged for each phase. (a) Flux in IOD Decay

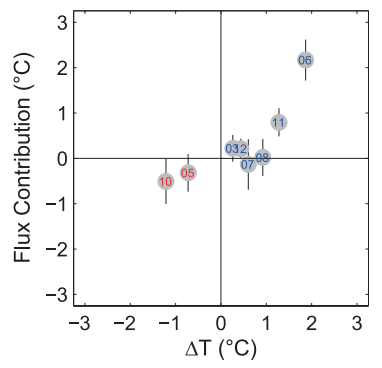

(b) Adv. in IOD Decay

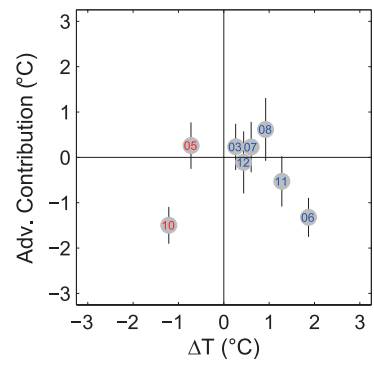

Fig. 4. As in Fig. 3, but for the decay phase of the IOD events. from east to west (Fig. 1a). For the minor cold events, however, the expanding of cold water already ceased at this phase. Climatological southward currents and their anomalous warm advection were more effective and that acted to warm the MLT anomalies, although these contributions were insignificant. These results suggest that air-sea heat exchanges tend to terminate the anomalous condition, and that ocean advections have various effects during the decay phases of major/minor cold events.

For the two warm events, air-sea flux tended to cool the positive MLT anomalies, which was primarily due to reduced shortwave radiation under cloudy condition (e.g., Cai and Qiu 2013). In the decay of a major warm event in 2010, the anomalous eastward currents and anomalous zonal temperature gradients acted to cool the eastern Indian Ocean, as clarified in Fig. 1b. Although that was also true in the 2005 event but with small amplitude of zonal advections, anomalously warm meridional advection by anomalous southward current canceled and exceeded the effect.

\subsection{Cold/Warm events during 1993-2001}

To increase the sample number, we further analyzed cold/ warm events for 1993-2001, during which relatively-reliable observation datasets were obtained. We conducted a MLT balance analysis in almost the same manner, except for that the MLT change and horizontal temperature gradients were estimated by the Reynolds SST dataset (Reynolds et al. 2002). The climatologies were defined as the 20-year mean (1993-2012). The results were essentially the same including the two cold and three warm events during 1993-2001 (Supplement 2). The results also show that contributions of ocean advections have various effects during the decay phase of cold/warm events (Supplement 2d).

\section{Discussion and conclusions}

The present results demonstrate that ocean advections are responsible for the development of MLT anomalies in SETIO. Although some studies have suggested that anomalous latent heat flux may play a leading role for SST anomalies in SETIO (e.g., Baquero-Bernal et al. 2002), it is unlikely that the net heat flux mainly resulted in the SST anomalies associated with IOD events. To investigate this further, we also analyzed air-sea flux balance for a modified study area $\left(90^{\circ} \mathrm{E}-100^{\circ} \mathrm{E}, 10^{\circ} \mathrm{S}-0^{\circ} \mathrm{S}\right.$, not shown). The results were essentially the same; the flux balance at the buoy location $\left(5^{\circ} \mathrm{S}, 95^{\circ} \mathrm{E}\right)$ should be general in SETIO.

The present results also indicate that the relative importance of net air-sea flux and ocean advection for anomalous MLT differed in each case: development/decay phase and cold/warm events, as illustrated in a schematic (Supplement 3). This suggests that IOD includes a variety of feedback processes in its development/ decay phases depending on cold/warm event. In a cold event, it should be noted that the relative importance of surface heat flux and ocean horizontal/vertical advection differs significantly near the coasts of Sumatra and Java (Halkides and Lee 2009). Because our analysis was based on a single buoy location, a cold advection during the development phase was probably the advection of cold water originally entrained in the coastal region. In a broad sense, this situation can be interpreted as atmosphere-thermocline coupled feedback (Bjerknes feedback), consistent with initial hypotheses (Saji et al. 1999). In contrast, a warm event is probably developed via a combination of net air-sea flux and warm advections. The warm advections are partly the result of warm SST anomalies initiated by El Niño-induced heat flux anomalies in the central to northern Indian Ocean (Horii et al. 2013) and from anomalously weak entrainment of cold water in the coastal region (Hong et al. 2008). In other words, a cold event in SETIO is related to coastal upwelling of cold water with subsequent expanding, whereas a warm event can be interpreted as a warming of the Indian Ocean warm pool with subsequent eastward shift. After the peak, a major cold event is brought back to the normal condition by the anomalous net air-sea flux. The negative feedback is the result of a combination of reduced latent heat loss and enhanced shortwave radiation, consistent with previous findings (e.g., Tokinaga and 
Tanimoto 2004). The negative feedback due to air-sea fluxes is also true for a major warm event but with opposite signs. In addition, negative feedback can be given by ocean advections. As can be seen in Fig. 1b, an anomalous condition causes a collapse of itself due to zonal advections of colder water.

Some other mechanisms could also be responsible for IOD decay. As shown in Rao and Yamagata (2004), a westerly wind burst could break anomalous condition of a cold event (Fig. 1a) through advection of warm water from west to east in the equatorial region. Considering the signal-to-noise ratio, the effect of intraseasonal variation would become relatively large in minor IOD events, which could be one reason for the divergent contribution of ocean advections during the decay phase (Fig. 4b). To clarify these mechanisms, heat balance analyses should be conducted in the equatorial region in future work.

IOD events during the 2000s have provided an unprecedented opportunity to quantify possible ocean-atmosphere feedback processes that produce anomalous SST in SETIO. Because it is still unclear if the present thermodynamic balance is general in the coastal area, further observational study for the coast of Sumatra and Java are desirable. This will further contribute to validating and advancing ocean-atmosphere coupled models for climate prediction. A next goal is to examine a possible decadal change in the frequency of IOD occurrence. Based on the present results, it is important to predict and quantify ocean advections to understand the occurrence of positive IOD. An important question is whether the frequent occurrence of positive IOD events during the recent decade is linked with the global warming trend (Zheng et al. 2010). Intensive and successive observations are needed for the eastern Indian Ocean, including the coasts of Sumatra and Java, to help clarify future changes of the tropical Indian Ocean.

\section{Acknowledgments}

We thank all of the members of the $R / V$ Mirai and $R / V$ Kaiyo cruises and the data processing team at the TRITON buoy cruise operations for their data management efforts. We also thank Lisan Yu for providing the OAFlux dataset, William B. Rossow for providing the ISCCP dataset, and the NOAA-Cooperative Institute for Research in Environmental Sciences Earth System Research Laboratory/Physical Sciences Division for providing reanalysis data. TMI-SST data were produced by Remote Sensing Systems (http://www.remss.com). OSCAR data were provided by Earth and Space Research. The Argo float data were collected and made freely available by the International Argo Project and the national programs that contribute to it (http://www.argo.ucsd.edu, http:// wo.jcommops.org/cgi-bin/WebObjects/Argo).

\section{Supplement}

Supplement 1 shows anomalous components of the MLT balance during the IOD events. Supplement 2 shows scatterplots as in Fig. 3 and Fig. 4, but for the extended period (1993-2012). The conclusions of this study are illustrated schematically in Supplement 3.

\section{References}

Baquero-Bernal, A., M. Latif, and S. Legutke, 2002: On dipole-like variability of sea surface temperature in the tropical Indian Ocean. $J$. Phys. Oceanogr., 15, 1358-1368.

Bjerknes, J., 1969: Atmospheric teleconnections from the equatorial Pacific. Mon. Wea. Rev., 97, 163-172.

Bonjean, F., and G. S. E. Lagerloef, 2002: Diagnostic model and analysis of the surface currents in the tropical Pacific Ocean. J. Phys. Oceanogr., 32, 2938-2954.

Cai, W., and Y. Qiu, 2013: An observation-based assessment of nonlinear feedback processes associated with the Indian Ocean Dipole. $J$. Climate, 26, 2880-2890.

Cai, W., P. van Rensch, T. Cowan, and H. H. Hendon, 2011: Teleconnection pathways of ENSO and the IOD and the mechanisms for impacts on Australian rainfall. J. Climate, 24, 3910-3923.

Du, Y., W. Cai, and Y. Wu, 2013: A new type of the Indian Ocean Dipole since the mid-1970s. J. Climate, 28, 959-972.

Foltz, G. R., J. Vialard, B. P. Kumar, and M. J. McPhaden, 2010: Seasonal mixed layer heat balance of the southwestern tropical Indian Ocean. J. Climate, 23(4), 947-965.

Halkides, D. J., and T. Lee, 2009: Mechanisms controlling seasonal-tointerannual mixed layer temperature variability in the southeastern tropical Indian Ocean. J. Geophys. Res., 114, C02012, doi:10.1029/ 2008JC004949.

Hong, C.-C., T. Li, Lin Ho, and J.-S. Kug, 2008: Asymmetry of Indian Ocean dipole. Part I: Observational analysis. J. Climate, 21, 48344848, doi:10.1175/2008JCLI2222.1.

Horii, T., Y. Masumoto, I. Ueki, H. Hase, and K. Mizuno, 2009: Mixed layer temperature balance in the eastern Indian Ocean during the 2006 Indian Ocean dipole. J. Geophys. Res., 114, C07011, doi: 10.1029/2008JC005180.

Horii, T., I. Ueki, K. Ando, and K. Mizuno, 2013: Eastern Indian Ocean warming associated with the negative Indian Ocean dipole: A case study of the 2010 event. J. Geophys. Res., 118, doi:10.1002/jgrc. 20071.

Hosoda, S., T. Ohira, and T. Nakamura, 2008: A monthly mean dataset of global oceanic temperature and salinity derived from Argo float observations. JAMSTEC Rep. Res. Dev., 8, 47-59.

Kalnay, E., and co-authors, 1996: The NCEP/NCAR 40-year reanalysis project. Bull. Am. Meteorol. Soc., 77, 437-471.

Li, T., B. Wang, C.-P. Chang, and Y. Zhang, 2003: A theory for the Indian Ocean dipole-zonal mode. J. Atmos. Sci., 60, 2119-2135.

Liebmann, B., and C. A. Smith, 1996: Description of a complete (interpolated) outgoing longwave radiation dataset. Bull. Amer. Meteor. Soc., 77, 1275-1277.

Luo, J.-J., S. Masson, S. K. Behera, and T. Yamagata, 2007: Experimental forecasts of Indian Ocean dipole using a coupled OAGCM. $J$. Climate, 20, 2178-2190.

McPhaden, M. J., G. Meyers, K. Ando, Y. Masumoto, V. S. N. Murty, M. Ravichandran, F. Syamsudin, J. Vialard, L. Yu, and W. Yu, 2009: RAMA: The Research moored array for African-Asian-Australian monsoon analysis and prediction. Bull. Amer. Meteorol. Soc., 90, 459-480.

Paulson, C. A., and J. J. Simpson, 1977: Irradiance measurements in the upper ocean. J. Phys. Oceanogr., 7, 952-956.

Rao, S. A., and T. Yamagata, 2004: Abrupt termination of Indian Ocean dipole events in response to intraseasonal disturbances. Geophys. Res. Lett., 31, L19306, doi:10.1029/2004GL020842.

Rao, S. A., J.-J. Luo, S. K. Behera, and T. Yamagata, 2009: Generation and termination of Indian Ocean dipole events in 2003, 2006 and 2007. Clim. Dyn., 33, 751-767.

Reynolds, R. W., N. A. Rayner, T. M. Smith, D. C. Stokes, and W. Wang, 2002: An improved in situ and satellite SST analysis for climate. $J$. Climate, 15, 1609-1625.

Saji, N. H., and T. Yamagata, 2003: Possible impacts of Indian Ocean dipole mode events on global climate. Clim. Res., 25, 151-169.

Saji, N. H., B. H. Goswami, P. N. Vinayachandran, and T. Yamagata, 1999: A dipole mode in the tropical Indian Ocean. Nature, 401, 360-363.

Schott, F. A., S.-P. Xie, and J. P. McCreary Jr., 2009: Indian Ocean circulation and climate variability. Rev. Geophys., 47, RG1002, doi:10.1029/ 2007RG000245

Sprintall, J., and M. Tomczak, 1992: Evidence of the barrier layer in the surface layer of the tropics. J. Geophys. Res., 97(C5), 7305-7316.

Tokinaga, H., and Y. Tanimoto, 2004: Seasonal transition of SST anomalies in the tropical Indian Ocean during El Niño and Indian Ocean Dipole years. J. Meteor. Soc. Japan, 82, 1007-1018.

Webster, P. J., A. M. Moore, J. P. Loschnigg, and R. R. Leben, 1999: Coupled ocean-atmosphere dynamics in the Indian Ocean during 199798. Nature, 401, 356-360.

Xie, S.-P., and S. G. H. Philander, 1994: A coupled ocean-atmosphere model of relevance to the ITCZ in the eastern Pacific. Tellus, 46A, 340-350.

Xie, S.-P., C. Deser, G. A. Vecchi, J. Ma, H. Teng, and A. T. Wittenberg, 2010: Global warming pattern formation: Sea surface temperature and rainfall. J. Climate, 23, 966-986.

Yu, L., X. Jin, and R. A. Weller, 2007: Annual, seasonal, and interannual variability of air-sea heat fluxes in the Indian Ocean. J. Climate, 20, 3190-3209.

Zhang, Y., W. B. Rossow, A. A. Lacis, V. Oinas, and M. I. Mishchenko, 2004: Calculation of radiative fluxes from the surface to top of atmosphere based on ISCCP and other global data sets: Refinements of the radiative transfer model and the input data. J. Geophys. Res., 109, D19105, doi:10.1029/2003JD004457.

Zheng, X.-T., S.-P. Xie, G. A. Vecchi, Q. Liu, and J. Hafner, 2010: Indian Ocean dipole response to global warming: Analysis of ocean-atmospheric feedbacks in a coupled model. J. Climate, 23, 1240-1253.

Manuscript received 14 September 2013, accepted 30 October 2013 SOLA: http://www.jstage.jst.go.jp/browse/sola/ 